ISSN: 2162-3104 Print/ ISSN: 2166-3750 Online

Volume 8, Issue 4 (2018), pp. 1891-1913

(C) Journal of International Students

http://jistudents.org/

doi: 10.5281/zenodo. 1471734

\title{
Factors Influencing Chinese International Students' Strategic Language Learning at Ten Universities in the U.S.: A Mixed-Method Study
}

\author{
Yao $\mathrm{Fu}$ \\ University of Wisconsin-Whitewater \\ Crystal Machado \\ Indiana University of Pennsylvania \\ Zhenjie Weng \\ Ohio State University
}

\begin{abstract}
This QUAL-QUAN mixed-method study employed a sociocultural interpretive framework to describe the Language Learning Strategies used by Chinese international students at ten universities in the U.S. During phase one, we used typological and interpretive analysis to identify nine factors that influenced 15 students' strategy use at four universities. In phase two we employed regression analysis to study the influence of these factors and two others on 117 students' strategy use at six U.S. universities. While participation and English proficiency level predicted direct strategies like memory, cognitive and compensatory strategies, participation was identified as the sole predictor of indirect strategies, like metacognitive, affective and social strategies. Findings have implications for college administrators, faculty and students.
\end{abstract}

Keywords: language learning strategies, mixed-method study, social factors

The population of international students pursuing higher education in the U.S. has been continuously rising over the last ten years. According to the Institute of International Education (2016), 1,044,000 undergraduate and graduate foreign nationals studied at U.S. colleges and universities during the 2015-2016 academic year. During this time, the number of Chinese students enrolled at the undergraduate and graduate levels increased to $31.5 \%$, with a total of 328,547 students. This influx of English language learners at the collegiate level has prompted scholars to study the linguistic and cultural challenges Chinese international students face in their host countries, such as acculturation, academic stress, and language anxiety. Empirical evidence shows that English language proficiency plays an essential role in students' ability to adapt to new cultural and academic environments (Li, Chen, \& Duamu, 2010; Liao \& Wei, 2014; Wang, 2012; Zhao, 2014). 
While there is growing awareness of the linguistic challenges Chinese students may face, we know very little about the Language Learning Strategies (LLS) they employ and the factors that influence their strategy choice. We used a QUAL-QUAN mixed-method approach to bridge this gap in the literature. We begin with a description of literature that serves as a foundation for this study. We then use Oxford's (1990) taxonomy of Language Learning Strategies and Gao's (2010) Sociocultural Interpretive Framework for Strategic Language Learning (SLL) to analyze data generated through 15 interviews and 117 surveys. We conclude with key findings and implications for enhancing teaching and learning in mainstream college classrooms.

\section{LITERATURE REVIEW}

This section provides a brief overview of literature that established the theoretical underpinning of this study. It includes a description of popular conceptual and empirical work related to second language acquisition, LLS and Gao's Sociocultural Interpretive Framework for second language acquisition (SLA), which guided the design of the research questions and survey.

\section{Two Theories of Second Language Acquisition}

From the 1990s to the current time, vigorous debates about the nature of learning a second language highlighted the differences between the two families of theories: the cognitive theory and social theory of SLA. Within the traditional cognitively oriented families of theories, SLA has long been viewed as "a matter of individual cognition, as a process that occurs in the mind of the learner, prompted by input that was seen to activate general cognitive processes" (Liddicoat \& Scarino, 2013, p 32). By contrast, the more recent sociocultural theoretical orientations emphasized that SLA involved social interactions with others, and language learning was mediated by context; it was a process whereby learners joined communities of language users, and they continuously expanded their communicative competence within these communities (Kern \& Liddicoat, 2008). Firth and Wagner (1997) used "bifurcation" to describe the distinction between the two families and the present situation of this ongoing debate; instead of considering the families as two diverging roads, they underscored the need to reconsider the diversity in both theories and to explore the relationship or balance between the two families.

\section{Gao's Sociocultural Interpretive Framework for Strategic Language Learning}

Given Firth and Wagner's (1997) call for a more balanced view of SLA, the sociocultural interpretative framework for strategic language learning proposed by Gao (2010) was used as the theoretical basis of this study. This framework was built on the realist position of agency and structure whereby learners' choice of LLS is mediated by contextual elements. This framework includes four components: context, setting, situated activity and self. Context refers to the macro environments for language learning which include, but are not limited to, social relationships, linguistic complexity, economic and political conditions. By contrast, setting is defined as the immediate environments where language learning transpires. For instance, the immediate environments consist of sociocultural institutions and various resources, tools, and artifacts that are accessible to the language learners. Situated activity stands for the interaction between language learners and contextual resources, such as social agents, sociocultural institutions, and materials and resources. Self is where learners' agency resides, including learners' capacities, motives and beliefs to "act in the learning process" (Gao, 2010, p. 30). 
In short, Gao's typology captures the essence of both families of theories and emphasizes the dynamic interconnections between learners and their surrounding environments. On the one hand, the framework acknowledges the importance of cognitive abilities (e.g., capacity) and psychological characteristics (e.g., motives) within individual learners. On the other, it draws attention to the interactions between learners, contextual resources, and social agents (e.g., peers and teachers) in their immediate surroundings and macro environments.

\section{Language Learning Strategies (LLS): Meaning and Classification}

In the field of SLA, one of the most dynamic areas of study has been LLS. LLS are steps taken by learners to facilitate language learning. Application of various LLS enables learners to effectively acquire language and store, retrieve and use information to enhance learning experience. To fully capture the richness of LLS, Oxford (1990) expanded the concept and defined it as "specific actions taken by the learner to make learning easier, faster, more enjoyable, more self-directed, more efficient, and more transferable to new situations" (p. 8). LLS are learners' conscious behaviors to enhance learning effectiveness and enrich learning with joy.

Among different categorization of LLS (e.g., Pintrich \& Garcia, 1991; Schmit \& Watanable, 2001), Oxford's (1990) comprehensive taxonomy has become a widely accepted classification system. It includes two broad categories: direct and indirect strategies. Direct strategies, which demand mental processing of the target language, include three subcategories: memory strategies, cognitive strategies, and compensation strategies. Memory strategies can assist learners to store and retrieve information, such as using rhymes and images to memorize unfamiliar words. Cognitive strategies involve various means (e.g., analysis and reasoning) that enable learners to manipulate the target language. Learners can also apply compensation strategies to use linguistic and nonlinguistic clues to guess word meanings.

Indirect strategies do not require direct involvement of the target language, which include metacognitive strategies, affective strategies, and social strategies. Metacognitive strategies emphasize conscious management of learning, such as setting up goals and reflecting on the learning process. By contrast, affective strategies (e.g., reducing anxiety and rewarding oneself) help regulate learners' emotions. As language learning entails communications, proper use of social strategies is also essential, such as asking questions for correction and clarification. Given the characteristics of the six categories, a good language learner should be able to use those strategies appropriately (Oxford, 1990).

\section{Factors Influencing Language Learning Strategies}

Apart from studies on the construct of LLS, the scholarly literature describes influencing factors of LLS. Many scholars have explored the self-level, an element of Gao's typology, which includes studies on motivation, learning preferences, personal traits and language proficiency. Although there is empirical evidence showing a positive relationship between students' motivation and language proficiency with their application of LLS (Aouri \& Zerhouni, 2017; Kamalizad \& Samuel, 2015; Rao, 2016), results on personal traits and learning preferences have been varied (Balci, 2017; Chen \& Huang, 2012; Kayaolu, 2013; Li \& Qin, 2006; Sahragard, Khajavi, \& Abbasian, 2016).

Academic majors and instructional methods are factors related to situated activity given that they may have strong effects on the interactions among students, instructors and learning materials. Rao and Liu (2011) found that social science majors employed more social strategies than science majors; Muniandy and Shuib (2016) found that while business majors preferred to use compensation strategies, communication majors applied more metacognitive and social 
strategies. For instructional methods, Wu (2015) reported that teachers' promotion of classroom participation and group learning enhanced students' interactions with their peers and instructors.

The assessment system in higher education institutions is related to the setting component; it reflects the immediate academic environment where learning occurs. Gao (2006) found that a shift from the Chinese to British evaluation approach enabled students to strategically apply key words instead of using rote memorization. Further, Yang (2017) found that even within the same social context (e.g., Taiwan), a change in assessment had substantial impacts on LLS. Students, who relied on direct strategies in test-oriented system, used dominantly indirect strategies in learning environment that promoted evaluation of both language and content knowledge.

Scholars also found context as an influencing factor. By comparing learning experiences in Taiwan and Philippines, Magno, Filho, and Lajom (2011) supported that language exposure and country of residence significantly influenced strategy use. Similarly, Hong-Nam and Szabo (2012) reported students' increased use of six strategies outlined in Oxford's (1990) comprehensive taxonomy from Korea to America.

Although LLS has been researched in various contexts, very few studies focus on Chinese adult learners (e.g., Gan, 2009; Xu, 2011); and even fewer have investigated both Chinese undergraduate and graduate students in an English as a second language learning context (e.g., Gao, 2006). Additionally, much of the literature that examines factors of LLS assumes a cognitive perspective (e.g., Li \& Qin, 2006; Weger, 2013); the immediate and social contexts in which learning occurs continues to be underexplored. Similarly, while abundant literature has explored international students' English learning experience in American language institutes (Hong-Nam \& Leavell, 2006; Mahalingam \& Yunus, 2017), insufficient research examines Chinese international students' LLS use in mainstream college classrooms across disciplines. This study attempts to bridge these gaps.

\section{Purpose of the Study and Research Questions}

This sequential exploratory QUAL-QUAN mixed-method study explored the English LLS that Chinese international students used while pursuing undergraduate and graduate degrees at ten different universities in the U.S. Figure 1 illustrates the theoretical framework of this study which is grounded in Oxford's (1990) taxonomy of LLS, which includes direct and indirect strategies; and Gao's (2010) Sociocultural Interpretative Framework: self, situated activity, setting, and sociocultural context.

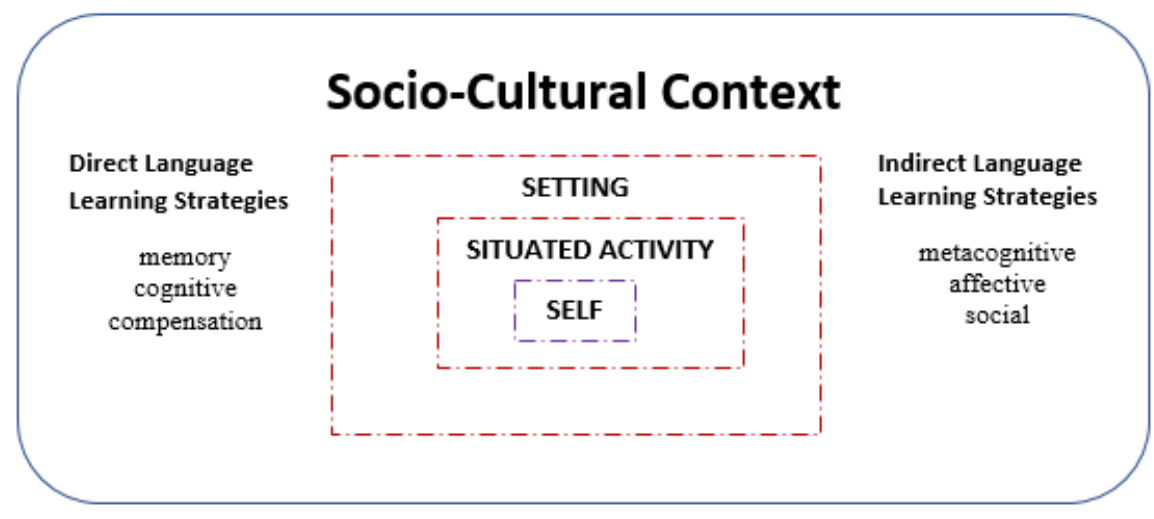

Figure 1. A sociocultural framework for language learning strategies 
This study was guided by the following research questions:

1. How did Chinese international students vary in their use of English language learning strategies?

2. What were the sociocultural factors that affected Chinese international students' choice of English language learning strategies?

3. To what extent did these sociocultural factors predict their use of English language learning strategies?

\section{METHODS AND DATA SOURCES}

To fully address the research questions, we utilized a QUAL-QUAN mixed-method approach (Creswell, 2013). Data were collected in two phases; starting with a qualitative phase that included 15 interviewees at four U.S. universities, followed by a second quantitative phase that included 117 respondents from six U.S. universities. Participants in both phases met the following three inclusion criteria:

1. They were Chinese international students above the age of 18 ;

2. They were working on undergraduate or graduate degrees in the U.S., and

3. They had been in the U.S. for less than ten years.

\section{Qualitative Phase 1: Instrumentation, Sampling, Interviewees and Procedures}

We collected qualitative data through semi-structured interviews. Details about the instrument, sampling procedure, and interviewees are presented in this section.

Instrumentation. The lead author, previously a Chinese international student, used Oxford's (1990) taxonomy of LLS and Gao's (2010) Sociocultural Interpretative Framework to guide development of the interview protocol. Multiple steps were employed to establish face validity (Marshall \& Rossman, 2016). Then, the second author, a university professor, who is a multilingual international faculty member reviewed the interview protocol multiple times. Following this, the instrument was reviewed by a panel of five faculty members who had expertise in this field (Marshall \& Rossman, 2016). Finally, the interview protocol was tested with two Chinese international students who met the study criteria. In addition to responding to the interview questions, they provided constructive feedback on how to avoid potential problems. The final version of the interview protocol included 11 closed and 31 open-ended questions (see Appendix A).

Sampling procedure. The snowball approach (Creswell, 2013) coupled with purposeful sampling procedures (Edmonson \& Irby, 2008) were used to include undergraduate, master's and doctoral students of different genders from four universities located in the northeastern regions of the U.S. Among the four universities, one was a large-sized university, one medium-sized and two were small.

Interviewees. As evident from Table 1, the 15 interviewees were diverse in terms of gender, education level, age, English proficiency and major. The sample included both males $(\mathrm{n}=7)$ and females $(\mathrm{n}=8)$. In terms of education background, the sample included the perspectives of undergraduate, master's, and doctoral students ( 5 of each). Of the five undergraduates, four were between the ages of 18 and 20 years old; one was 33 years old. The master's and doctoral 
students ranged in age from 22 to 30 years. All interviewees had studied in higher education institutions in both China and the U.S.

Based on their self-reported scores of the English as a Foreign Language (TOEFL) and the International English Language Testing System (IELTS), three interviewees (2, 3 and 9) could be classified as proficient and three as highly proficient (5, 6 and 14) in English. Based on GPA scores, five of the interviewees could be classified as excellent students (GPA = 4.0), six as very good (between 3.5 and 4) and two as good (between 3 and 3.5). Two students did not divulge their GPA scores because of their low academic achievement.

Table 1: Biographical Profiles of Interviewees

\begin{tabular}{|c|c|c|c|c|c|c|}
\hline I & Gender & Age & Education & Major & $\begin{array}{l}\text { TOEFL }(\mathrm{T}) / \\
\text { IELTS (I) }\end{array}$ & GPA \\
\hline 1 & $\mathrm{~F}$ & 27 & $\mathrm{D}$ & Composition and TESOL & N/A & 4.0 \\
\hline 2 & $\mathrm{~F}$ & 25 & $\mathrm{D}$ & Curriculum and Instruction & $\mathrm{T}: 98$ & 4.0 \\
\hline 3 & $\mathrm{M}$ & 30 & $\mathrm{D}$ & Math & $\mathrm{T}: 95$ & 3.98 \\
\hline 4 & M & 28 & $\mathrm{D}$ & Math & $\mathrm{T}: 80$ & 3.8 \\
\hline 5 & M & 27 & $\mathrm{D}$ & Psychology & $\mathrm{T}: 100$ & 4.0 \\
\hline 6 & M & 24 & M & MBA & $\mathrm{T}: 112$ & 3.84 \\
\hline 7 & M & 24 & M & $\mathrm{MBA}$ & I: 5.5 & 3.5 \\
\hline 8 & $\mathrm{~F}$ & 25 & M & Pop Culture & $\mathrm{T}: 81$ & 4.0 \\
\hline 9 & $\mathrm{~F}$ & 22 & M & TESOL & T: 98 & 3.97 \\
\hline 10 & $\mathrm{~F}$ & 22 & M & MBA & I: 5.5 & 3.23 \\
\hline 11 & M & 20 & $\mathrm{U}$ & Hospitality & N/A & 3.5 \\
\hline 12 & $\mathrm{~F}$ & 33 & $\mathrm{U}$ & Art Education & N/A & 4.0 \\
\hline 13 & $\mathrm{~F}$ & 22 & $\mathrm{U}$ & Accounting & I: 5.5 & 3.19 \\
\hline 14 & $\mathrm{M}$ & 22 & $\mathrm{U}$ & General Management & I: 7.5 & N/A \\
\hline 15 & $\mathrm{~F}$ & 18 & $\mathrm{U}$ & Pre-med & $\mathrm{T}: 63$ & N/A \\
\hline
\end{tabular}

Note. $\mathrm{U}=$ Undergraduate, $\mathrm{M}=$ Master's, $\mathrm{D}=$ Doctoral

Procedures: Data collection and data quality. Each interview lasted between 45 - 90 minutes. Before the interview started, the interviewer explained the study purpose and provided illustrative examples of LLS to ensure that interviewees had sufficient background knowledge. The interviewer elaborated and provided additional clarification when interviewees encountered difficulty in understanding words and phrases (e.g., learning preferences). 
Several steps were taken to enhance trustworthiness of the data. First, we conducted the interviews in Chinese to enhance interviewees' comfort level (Squires, 2009). Second, we transcribed and analyzed the data in Chinese to limit misinterpretation (Squires, 2009). Additionally, we provided interviewees with an opportunity to verify data through member check (Creswell, 2007). Next, the third author, who is also Chinese, used Gao's (2010) typologies, self, situated activity, setting, and context, to code each transcript (Hatch, 2002). During the data reduction process the two Chinese authors used interpretive analysis to identify patterns, themes, and relationships between and across typologies. They used memoing and peer debriefing to minimize author bias and eliminate the over or under emphasis of ideas (Edmonson \& Irby, 2008). In addition to providing answers to the first research question (discussed in the result section) the qualitative data were used to develop the Likert-scale survey titled Factors Influencing English Learning Strategies (FIELS); this was used to collect quantitative data in phase two of the study.

\section{Quantitative Phase 2: Instrumentation, Sampling, Survey Respondents and Procedures}

Upon completion of the first phase, we used two surveys to elicit quantitative data from 117 respondents. This section describes the instrument, sampling procedure, survey respondents, data collection and analysis employed in phase two.

Instrumentation. Two instruments were used in the second phase to collect quantitative data. The first was the Strategy Inventory for Language Learning (SILL) version 7.0 developed by Oxford (1989). This survey includes 50 items in five-point Likert scale format specifically designed for students of English as a second or foreign language. Russell (2010) reported that the instrument has high internal consistency with an alpha value of .951. Organized in six parts, this instrument helped us examine Chinese international students' LLS use under the six subcategories of Oxford's taxonomy: memory, cognitive, compensatory, metacognitive, affective and social strategies.

The second was the FIELS survey (see Appendix B). This 18-item instrument in Likert scale format facilitated collection of demographic data as well as data related to influencing factors of LLS. The first five items elicited basic demographic information such as age, gender, and nationality. While the current study included only Chinese international students in the U.S., the instrument may be used in other countries and contexts. Questions 6-7, which elicited information about respondents' educational level and English proficiency, were included because there is a dearth of literature on how these two factors might influence Chinese international students' LLS choice. The last nine questions were developed based on the nine significant factors uncovered through the qualitative phase (see Table 2), described in the following section. In summary, questions 6-16 helped garner data regarding 11 possible factors of LLS that would be further examined with multiple regression analysis.

Sampling procedure. We used the snowball approach (Creswell, 2013) and purposeful sampling procedures (Edmonson \& Irby, 2008) to recruit 117 Chinese international students currently enrolled in six U.S. universities. We initially chose students we already knew who met all the selection criterion. We then used the snowball approach; respondents were encouraged to forward the surveys to both males and females from different majors and academic backgrounds who met the inclusion criteria (i.e., undergraduate, master's and doctoral levels). 
Survey respondents. The average age of 117 respondents was about 26 years old, with the youngest being 18 and the oldest 47 . The sample included a similar number of males and females. Respondents were pursuing 25 different majors in a wide variety of academic disciplines, such as education, business, mathematics, political science, and engineering. In terms of educational level, $44 \%$ were currently pursuing a bachelor's degree, $27 \%$ a master's degree, and $28 \%$ a doctoral degree.

Procedures: Data collection, analysis and data quality. In the second phase, respondents were first asked to complete the SILL survey (Oxford, 1989), an instrument widely adopted by researchers to assess language learning strategies (Oxford \& Burry-Stock, 1995). Following this they were directed to the FIELS survey, which was designed to uncover the factors that may influence Chinese international students' LLS. Respondents had access to both paper and online versions of the two surveys and were encouraged to invite their friends and families who met the criteria to participate in the study. The alpha value of the FIELS was .825; this was deemed acceptable because it was greater than the recommended .80 (Leedy \& Ormrod, 2005). Upon data collection, the SPSS software was utilized to perform statistical analysis; descriptive statistics were run to identify respondents' strategy use and multiple regression was performed to identify factors that predict strategy use.

\section{RESULTS AND KEY FINDINGS}

We analyzed data for each phase separately and sequentially. The two data streams were then merged to answer the research questions. In the first phase, we used typological and interpretive analysis to make sense of interview data; this resulted in identification of nine factors that influenced interviewees' use of LLS. The second phase examined the variance in using the LLS across a larger sample and the effect of 11 factors (two additional demographic variables were added) in predicting respondents' use of LLS. This section describes the key findings that emerged.

\begin{tabular}{llc}
\hline Gao's Typology & \multicolumn{1}{c}{ Influencing Factors } & Frequency \\
\hline Self & Factor 1: Learning preferences & 15 \\
& Factor 2: Motivation of English learning & 13 \\
Situated Activity & Factor 3: Skills and learning content required by majors & 14 \\
& Factor 4: Active class participation promoted by instructors & 9 \\
& Factor 5: Critical thinking skills promoted by instructors & 6 \\
Setting & Factor 6: Variety of assessments used by instructors & 11 \\
& Factor 7: Instructor availability in and after class & 8 \\
Context & Factor 8: Immersion in authentic English-speaking environment & 15 \\
& Factor 9: Exposure to the social and cultural values of the U.S. & 13 \\
\hline
\end{tabular}




\section{Qualitative Phase 1: Results and Key Findings}

The major purpose of the interviews was to explore Chinese international students' use of LLS. Interview questions were aligned with Gao's (2010) four typologies, self, situated activity, setting and context. We used Hatch's (2002) typological analysis to code and quantize the qualitative data. The nine categories that emerged are listed in Table 2 as "influencing factors," along with the number of times each was referenced across the 15 interviews.

\section{Table 2: Nine Leading Factors Organized by Gao's Topology with Frequencies}

As evident from Table 2, interviewees made many more comments related to situated activity $(n=29)$ followed by self and context $(n=28$ for both) and setting $(n=19)$. Although listed individually in Table 2, these factors were interrelated and influenced Chinese international students' use of LLS in a variety of ways. Details relevant to each element of Gao's typology is presented in the following section along with illustrative quotes.

Self. Learning preferences and motivation to learn English are essential factors related to Gao's first typology of self. A total of 28 comments related to this domain across the 15 interviews. Interviewees identified a variety of learning preferences; they described themselves as solitary, social, visual, auditory, and logical learners. Interpretive analysis revealed that the majority were solitary learners, with varied preference for visual, auditory, or logical learning preferences. Visual learners liked to watch TV shows and movies to study English. Auditory learners preferred learning through music, like rap. Logical learners relied on patterns or logic behind English concepts. As evident from the quote below, in most cases, interviewees demonstrated multiple learning preferences. A solitary, visual learner said, "I would like to study alone and set up my own study pace. Group study requires a lot of compromise." She continued:

I prefer learning English through reading. When I read, I highlight unfamiliar words, key words, using different colors. Or sometimes I use different marks to indicate varying significance of the information, through which I learn new vocabulary and improve my reading skills. (Interviewee 9)

Motivation to learn English was another influential factor related to the first typology. Specifically, two motivators, self-interest and practical reasons, were found to exert substantial influence. A few students mentioned that they kept learning English, driven by personal interest in the language; however, more than half of the interviewees were driven by external pressures because English is perceived as the lingua franca worldwide. Once they came to the U.S., they were also driven by their desire to reduce miscommunication and access major-related information through interaction with native English speakers. The following quote indicated that some interviewees were willing to step out of their comfort zone to pursue learning opportunities.

I was not a party-goer before, but I found parties provided good opportunities to obtain different information (good or bad) from attendees who were from different majors and to practice my speaking skills. So sometimes I forced myself to go to those parties. (Interviewee 6)

Situated activity. In this category, skills and learning content required by majors, active class participation, and critical thinking skills promoted by instructors were identified as influential factors. A total of 29 comments related to this domain across the 15 interviews. As was expected, interviewees' comments confirmed that each academic discipline had its own discourse and objectives, which included a demand for different sets of desirable skills. For 
instance, students from business or accounting majors spent a great deal of their time developing their mathematical skills, and less time developing their communicative or writing skills. In contrast, education majors made concerted effort to improve their writing and speaking skills. Social media and communication majors focused on developing their reading, communicative, and critical thinking abilities. This is reflected in the illustrative quote of a pop-culture major:

My major requires lots of reading. I spend lots of time on vocabulary and figuring out the meaning of each word and each sentence, which takes a long time in reading. But through practice, I learned to first focus on introduction, conclusion, and then reference pages to get a sense of the main idea of an article or a book. Also, if it is a book, I would only read several chapters, rather than reading the whole book. (Interviewee 8)

From the quote above, it is apparent that reading requirements place greater demands on non-native speakers of English. The interviewee addressed this challenge by employing cognitive and metacognitive strategies, among others, to increase her reading and comprehension skills. Rather than allowing herself to get overwhelmed by the volume of reading, she set realistic goals for herself and focused more on the content included in some sections.

Qualitative data highlighted difference in Chinese and U.S. faculty expectations about student engagement practices, and the LLS students chose to adapt to their new environments. Several interviewees reported that in Chinese classrooms attentive listening and note taking were valued and practiced. In that context, they complied with the expectations and focused more on rote memorization and intensive note-taking in class. In the U.S., on the other hand, critical thinking and active learning were valued. To be successful they had to learn how to plan and deliver in-class presentations and contribute to classroom discussions. The comment below illustrates the apprehension an interviewee felt and the cognitive and affective strategies she employed to make her voice heard during class discussions:

I had a tough time in public speaking. My professor thought I was too quiet and required me to speak more in class, which gave me a lot of stress. Sometimes I wanted to speak, but I was always looking for the right time. Most of the time I just missed the chance. To conquer that, I wrote down what I wanted to say and then raised my hand to get attention. (Interviewee 11)

The interviewee's stress can be attributed, not just to limited proficiency in English, but also to cross-cultural differences in communication. Like her, other interviewees used cognitive strategies to reduce memory workload and affective strategies to reduce anxiety in speaking.

Another cross-cultural difference relates to the power-difference between teacher and student. In China, faculty are held in high esteem, and students are encouraged to master the content as it is, rather than form their own opinions; in the U.S., however, faculty encourage students to think critically, not just through oral communications, but also in writing ( $\mathrm{Li}, 2011$; $\mathrm{Li}, 2007)$. The educational difference between the two countries is reflected in the comment below:

My professor stressed critical thinking in writing so much that I had to read lots of articles and did research to have a comprehensive understanding of certain topics to correctly critique an idea, which I never experienced before in China. (Interviewee 2)

The expectation that students critique the ideas of scholars and other students propelled the interviewee to engage in after-class research, gain deeper understanding of the topics in question, and become an independent thinker and doer.

Setting. The two factors in this category related to instruction and assessment practices. A total of 19 comments related to this domain across the 15 interviews. Students felt a greater 
need to engage with U.S. faculty after class than they did with Chinese faculty. Interviewees explained that faculty in China left immediately after class and it was difficult to reach them at other times. They went on to explain that they did not feel the need to contact faculty outside of class because they had already been told what to expect on tests, which could be accomplished through memorization. The quote below explains why interviewees felt the need to contact U.S. faculty more than their Chinese counterparts, and how they actively used social strategies to improve their learning outcomes:

...but in the U.S., professors rarely divulge test content, so I had to study hard and efficiently. If I have any questions, I email my professors or visit them during office hours. Sometimes I ask questions directly after the class. (Interviewee 10)

Another factor that influenced their LLS was the nature of assessments employed by Chinese professors in college classrooms. Interviewees explained that Chinese faculty were more product- and test-oriented. Students' performances in and after class were evaluated solely based on test scores. One interviewee said:

In China, there were mainly midterm exams and final exams. There were no other assessments, but in the U.S., assessments were varied at different levels. For example, we had quizzes which took small portion of points; we had midterm exams and sometimes we had individual or group projects, which took up essential points. So, our academic performance was evaluated holistically in multiple ways. (Interviewee 3)

This approach to assessing learning outcomes forced interviewees to shift from their use of memorization to a variety of cognitive, social and metacognitive LLS. For example, instead of relying on rote-memory to pass tests as she did in China, one interviewee (Interviewee 14) began to employ intensive cognitive strategies because many of her assignments were essays. She felt the need to switch her focus from memorizing English words to synthesizing and reorganizing information. She had to embrace English writing conventions, such as including background information and thesis statements in introductory paragraph.

Context. A total of 28 comments related to this domain across the 15 interviews. Immersion in authentic English-speaking environments and exposure to the social and cultural values of Americans were two related factors that influenced interviewees' LLS use. Living in an English-speaking context, interviewees acquired English both intentionally and unintentionally. In the case of the former, interviewees mentioned that they made a conscious effort to watch English movies without subtitles to practice their listening skills. They improved their spoken English by booking flights, calling embassies, participating in school activities, staying with host families, and noticing diverse ways of greetings. They mentioned they became more attentive to professional manners and discourse, like how to send an email to a professor. Unintentional language learning occurred more organically with the increased exposure to social and cultural values of Americans. Many interviewees mentioned they learned different English expressions by going to parties, playing sports, and visiting American families. For example, one interviewee found out that "drink like a fish," means "drink excessive amount of alcohol" while socializing with an American friend.

Interviewees described how they gained awareness of language diversities in the U.S. Some interviewees mentioned that while talking to native English speakers they consciously paid attention to their interlocutors' grammar use and authentic English expressions. This opportunity, which had been lacking in China, helped enhance the learning process. They started to recognize that English language intermingled with American culture. One student elucidated his awareness 
of different English accents between east Pennsylvania and west Pennsylvania, New Yorkers and Southerners, as well as African American vernacular and standard American English.

I had not experienced those English differences before in China. I realized that these different accents also reflected different personalities and mindset of people. Each accent represents a culture. When I talked to people with different accents, I tried to respect those cultures and adapt to those cultures. This enhanced my communicative efficiency. (Interviewee 7)

This quote shows the interviewee engaged in metacognitive reflection about different accents and dialects; it illustrates skilled utilization of LLS to successfully master oral English communication. It also underscores the importance of providing cultural immersion to enhance language acquisition and cultural awareness.

\section{Quantitative Phase 2: Results and Key Findings}

Upon completion of the first phase, we conducted statistical analysis to further examine (1) the variance in Chinese students' LLS use, and (2) the extent to which the eleven potential factors highlighted in the FIELS survey contribute to such variance. To begin, descriptive statistics were run to identify the LLS preferences of survey respondents. Based on Oxford's (1989) interpretation of the SILL score, survey respondents' overall use of strategies was high $(M=3.57, S D=.50)$. The mean scores of direct strategy use $(M=3.56, S D=.46)$ and indirect strategy use $(M=3.61, S D=.63)$ confirmed that the respondents frequently used both.

A close look at the six subcategories revealed that four were used more frequently than others. These included metacognitive strategies $(M=3.80, S D=.71)$, followed by social strategies $(M$ $=3.78, S D=.75)$, cognitive

Table 3: Predicting Overall Strategy Use

\begin{tabular}{ccccc}
\hline Predictor & B & SE B & $\beta$ & Sig. \\
\hline (Constant) & 106.017 & 16.566 & & .000 \\
\hline Educational Level & -5.188 & 3.711 & -.166 & .165 \\
\hline English Proficiency & 5.929 & 2.957 & .216 & .048 \\
\hline Learning Styles & -.256 & 3.380 & -.009 & .940 \\
\hline English Learning & .904 & 3.484 & .032 & .796 \\
Motivation & & & & \\
\hline Major Skills \& Content & -4.330 & 3.728 & -.141 & .248 \\
\hline Active Class & 13.038 & 3.584 & .416 & .000 \\
Participation & & & & .266 \\
\hline Critical Thinking Skills & -3.926 & 3.511 & -.125 & .265 \\
\hline Variety of Assessments & 2.797 & 3.694 & .081 & .451 \\
\hline Instructor Availability & 1.860 & 2.886 & .070 & .521 \\
\hline English-Speaking & 1.982 & 3.597 & .063 & .583 \\
\hline $\begin{array}{c}\text { Environment } \\
\text { Social \& Cultural Values }\end{array}$ & 4.475 & 3.350 & .146 & \\
\hline
\end{tabular}
strategies $(M=3.70, S D=.53)$, and compensation strategies $(M=3.62$, $S D=.54)$. Memory strategies $(M=$ 3.27, $S D=.60)$ and affective strategies $(M=3.12, S D=.80)$ were used occasionally; the means scores of individual items under memory strategies or affective strategies ranged between 2.5 and 3.4. Multiple regressions were performed to explore the degree to which the eleven factors may predict 117 survey respondents' LLS use. We first examined how these factors predicted the overall mean score of the 50 items. The results of the regression indicated that two factors explained $30.8 \%$ of the variance $\left(R^{2}=.308\right)$ in overall strategy use, $F(10,106)=3.85$, $p<$ 0.001 ; these were educational level $(\beta=.22, p<0.05)$ and participation $(\beta=.41, p<0.001)$ (see Table 3$)$. 
Table 4: Predicting Direct Strategy Use

\begin{tabular}{ccccc}
\hline Predictor & B & SE B & $\beta$ & Sig. \\
\hline (Constant) & 67.342 & 8.945 & & .000 \\
\hline Educational Level & -2.738 & 2.004 & -.168 & .175 \\
\hline English Proficiency & 4.102 & 1.592 & .286 & .010 \\
\hline Learning Styles & -.498 & 1.824 & -.032 & .785 \\
\hline English Learning Motivation & .118 & 1.881 & .008 & .950 \\
\hline Major Skills \& Content & -1.501 & 2.013 & -.093 & .458 \\
\hline Active Class Participation & 5.525 & 1.935 & .336 & .005 \\
\hline Critical Thinking Skills & -2.129 & 1.895 & -.129 & .264 \\
\hline Variety of Assessments & 1.772 & 1.978 & .099 & .373 \\
\hline Instructor Availability & .704 & 1.558 & .051 & .653 \\
\hline English-Speaking Environment & .814 & 1.940 & .049 & .676 \\
\hline Social \& Cultural Values & 2.475 & 1.789 & .155 & .170 \\
\hline
\end{tabular}

Table 5: Predicting Indirect Strategy Use

\begin{tabular}{|c|c|c|c|c|}
\hline Predictor & B & SE B & $\beta$ & Sig. \\
\hline (Constant) & 37.465 & 9.587 & & .000 \\
\hline Educational Level & -2.091 & 2.123 & -.120 & .327 \\
\hline English Proficiency & 1.949 & 1.711 & .126 & .257 \\
\hline Learning Styles & .628 & 1.951 & .038 & .748 \\
\hline $\begin{array}{c}\text { English Learning } \\
\text { Motivation }\end{array}$ & .596 & 2.011 & .037 & .768 \\
\hline Major Skills \& Content & -2.409 & 2.153 & -.140 & .266 \\
\hline $\begin{array}{l}\text { Active Class } \\
\text { Participation }\end{array}$ & 6.911 & 2.046 & .393 & .001 \\
\hline Critical Thinking Skills & -1.192 & 2.017 & -.067 & .556 \\
\hline Variety of Assessments & .267 & 2.114 & .014 & .900 \\
\hline Instructor Availability & 1.258 & 1.659 & .085 & .450 \\
\hline $\begin{array}{c}\text { English-Speaking } \\
\text { Environment }\end{array}$ & .917 & 2.072 & .052 & .659 \\
\hline $\begin{array}{c}\text { Social \& Cultural } \\
\text { Values }\end{array}$ & 2.371 & 1.937 & .138 & .224 \\
\hline
\end{tabular}

Post hoc power analysis for this multiple regression with eleven predictors was conducted in $\mathrm{G}^{*}$ Power to determine the power of using an alpha of 0.05 , a sample size of 117 and an effect size of $\mathrm{f}^{2}=.445$; the analysis yielded a strong power of 0.99 .

We then examined the effects of these factors on the two major categories. English proficiency level $(\beta=.30, p<$ $0.01)$ and participation $(\beta=.34, p$ $<0.01)$ were identified as significant predictors of direct strategies; they explained $27.1 \%$ of the variance $\left(R^{2}=.271\right), F(10$, 106) $=3.24, p<0.001$ (see Table 4).

Participation $(\beta=.40, p$ $<0.01)$ was identified as the only significant predictor of indirect strategy use $\left(R^{2}=.27, F(10,106)\right.$ $=3.32, p<0.001$ ) (see Table 5). Post hoc power analysis for the above two multiple regressions also led to a strong power of 0.99 using an alpha of 0.05 , a sample size of 117 and an effect size of $\mathrm{f}^{2}$ $=.37$.

Finally, the factors that predicted the six subcategories, namely memory, cognitive, compensation, metacognitive, affective and social strategies, were identified. It was found that participation $(\beta=.35, p$ $<0.01)$ predicted memory strategies $\left(R^{2}=.18, F(10,106)=\right.$ 2.01, $p<0.05)$; participation $(\beta=$ .33, $p<0.01)$ predicted metacognitive strategies $\left(R^{2}=.22\right.$, $F(10,106)=2.56, p<0.01)$; and participation $(\beta=.47, p<0.001)$ predicted affective strategies $\left(R^{2}=\right.$ $.25, F(10,106)=3.00, p<0.01)$.

English proficiency level $(\beta=.27, p<0.01)$ predicted cognitive strategies, accounting for $31.9 \%$ of the variance $(F(10,106)=4.12, p<0.001)$. Three predictors, motivation $(\beta=.25, p<0.05)$, 
participation $(\beta=.24, p<0.05)$, and exposure to social and cultural values $(\beta=.30, p<0.01)$ explained $29.7 \%$ of the variance in social strategies $(F(10,106)=3.73, p<0.001)$. Post hoc power analysis for all the five multiple regressions yielded sufficient powers ranging from .93 to .99 , which evidenced adequate sample size.

\section{DISCUSSION AND IMPLICATIONS}

The findings that emerged from analysis of both phases not only addressed the three research questions, but also highlight implications for faculty, administrators and students who interact with Chinese international students in the U.S. This section presents a discussion of the findings, organized by research questions with related implications.

\section{Discussion of Findings}

Variability in use of English language strategies. Research question 1 was designed to explore how Chinese international students vary in their use of English LLS. Magno, Filho, and Lajom (2011) found in a second language learning context, learners improved their overall strategy use, with largest increases in cognitive, metacognitive and social strategies. This study revealed a similar trend. Interviewees and survey respondents showed a strong preference for metacognitive and social strategies rather than memory strategies which require limited investment of time and effort. This can be attributed to the sociocultural contexts in the U.S. which is described in Hofstede's (1984) work. Classrooms in the U.S. are characterized by individualistic and competitive atmosphere with low degree of power distance. On the contrary, East Asian classrooms are characterized as collectivist with hierarchical order (Lee, 2007). The Chinese educational system heavily relies on teacher-centered instruction, rote-memorialization, note-taking, and test-oriented study; in the U.S., on the other hand, the emphasis is placed on critical thinking, active classroom participation, and comprehensive evaluation of students' performance. The cognitive dissonance, which students experience as they shift from one context to another, can influence their choice of LLS. This study confirmed that increased expectation of well-developed communicative and reading skills along with strong promotion of individual expressions and values compelled students to become less reliant on direct strategies and achieve more balanced application of direct and indirect strategies.

Factors that affected Chinese international students' choice of LLS. Research Question 2 was designed to identify the sociocultural factors that affected Chinese international students' choice of English LLS. Interview data collected during phase 1 coupled with existing empirical research helped answer this question. In the past two decades, scholars have found that learning preferences and motivation could impact English learners' strategy use (Aouri \& Zerhouni, 2017; Balci, 2017; Ehrman \& Oxford, 1989; Nasihah \& Cahyono, 2017). Interview data generated through the current study confirms that variance in learning preferences and motivations strongly affected Chinese international students' strategy preferences at U.S. universities. Studies have also revealed that differences in academic majors and teaching methods may lead to various applications of LLS (Muniandy \& Shuib, 2016; Wu, 2015). In addition to corroborating these findings, this study pinpointed that the core skills and knowledge required by different majors, active class participation and critical thinking skills promoted by instructors at universities in the U.S. motivates students to employ different strategies. For example, when instructors encourage active participation and critical thinking students were more likely to 
employ a variety of LLS strategies to improve their learning outcomes, such as using cognitive strategies to reduce memory workload and affective strategies to alleviate anxiety in English communication. These results confirm that Gao's (2010) typology facilitates a more comprehensive examination of factors that influence Chinese international students' English LLS at multiple levels.

Extent to which identified factors influence Chinese international students' use of English LLS. Research Question 3 was designed to examine the extent to which the sociocultural factors predicted students' use of English LLS. Survey data collected during phase 2 helped answer this question. Cohen (2000) and $\mathrm{Li} \mathrm{(2002)}$ found that proficiency level predicted metacognitive strategies. Contradictory to their findings, this study supported that participation and English proficiency level predicted direct strategies; while only participation predicted indirect strategies. In other words, participation was the sole significant indicator for both direct and indirect strategies. One plausible explanation for these inconsistent findings is the context of the studies and participants' background. Li's (2002) and Cohen's (2000) participants were English learners studying at language institutes in an English as a foreign language context. This study included participants who were English language learners and users in mainstream classrooms at U.S. universities. The results of this study highlight the need to use a sociocultural lens to further analyze Chinese international graduate and undergraduate students' LLS in mainstream classrooms because they encounter the dual challenge of enhancing English proficiency and acquiring content knowledge and skills in subject areas.

\section{Implications of the Study}

This study has several implications for administrators, faculty, Chinese international students and American students at U.S. universities.

1. This study revealed that many Chinese international students become familiar with classroom discourse when they are immersed in the U.S. educational experience. A sudden shift from one academic culture to another has the potential to make some students feel anxious, isolated and lonely (Crede \& Borrego, 2014; Sawir, Marginson, Deumert, Nyland, \& Ramia, 2008). Administrators and faculty will be able to serve this population more fully when they understand the academic, sociocultural, and psychological challenges involved in cross-cultural adjustment, and develop multicultural sensitivity and competence. Offices of international programs could relieve student stress by providing Chinese international students with access to synchronous or asynchronous webinars and/or audio and video tutorials while they are still in their home country to help them understand the norms and procedures that American students take for granted. Knowledge of what their immediate future holds may help them better prepare for the American experience and alleviate some of the anxiety they currently face during class discussions (Bartram, 2008; Lillyman \& Bennett, 2014). Faculty can help students better prepare for active student engagement and critical thinking by making instructions and requirements more transparent by including additional details about the expectations in syllabi; providing students with access to examples of student work; pairing students with a mentor and/or study buddy.

2. Interviewees and survey respondents expressed a preference for deep strategies such as reading, writing, summarizing, and looking for patterns in English rather than surface strategies. This time-consuming process, beneficial though it was, sometimes prevented interviewees from reading everything that was assigned. Faculty should be cognizant of the demands that reading assignments place on nonnative speakers. They can reduce some of the 
anxiety that students experience by explicitly teaching study skills or directing students to the university's Writing Center, if they have one, so that students can receive specialized help.

3. To increase Chinese international students' English proficiency level, which was identified as a predictor of direct strategies like memory, cognitive, and compensatory strategies, faculty could create more time for students to process information by facilitating multimodal learning. Minor changes like uploading content related to the assigned readings in other formats (e.g., audio, visual and web-based resources) to their learning management systems ahead of time would go a long way in benefiting students who self-identified as solitary learners with social, visual, auditory and logical learning preferences.

4. Participation was identified as the sole predictor of both direct and indirect strategies. Carroll (2015) broadly defined participation as active engagement that includes thinking and speaking. To further increase international student participation faculty should develop holistic understanding of participation practices. They should target both cognitive and oral participation. For example, they could enhance students' learning experience by orchestrating some class discussions online. This will give Chinese (and other) international students additional time to read and digest their peers' responses, craft their own responses, and fully participate in discussions without the added anxiety that comes with oral discussions in class. Additionally, faculty should recognize that "a continuum from peripheral to central participation" may reflect students' varying degrees of prior knowledge on the subject matter (Straker, 2016, p. 313). When international students have little experience and understanding of the historical context and norms of American education, faculty should help them unpack these norms with detailed directions and adequate scaffolding. This will make it possible for them to gradually move from peripheral (inactive) to central (active) participation.

5. In the absence of cross-cultural training, faculty and administrators who have had limited exposure to Chinese culture may misinterpret international students' verbal and nonverbal cues; this could lead to further confusion and frustration. Offices of international programs and centers that promote excellence in teaching at universities should offer workshops that provide administrators, faculty and staff with a working knowledge of the unique features of the Chinese educational system, and the influence it may continue to have on students' social and academic behavior and learning outcomes. They can use this information to make existing programs and practices more inclusive. This will help Chinese (and other international) students transition more smoothly into their new environment.

6. Finally, this study revealed that exposure to social and cultural values was predictive of social strategy uses. This finding underscores the importance of providing international students with cross-cultural experience and opportunities to interact with native speakers of English in a variety of academic and non-academic settings. Faculty could capitalize on the increased number of Chinese international students in their classrooms by encouraging them, and other cultural groups, to bring different cultural issues, projects, and perspectives into classroom. In addition to promoting and valuing the ideas and identities of diverse students it will enhance the learning experience of all students and the intercultural competence of faculty by working with international students. Faculty could also work collaboratively with the international education office and local community to design assignments and activities that promote Chinese students' exposure to cultural and linguistic diversity and authentic interaction with American peers and community members. There is evidence to show that many American students do not feel comfortable interacting with international students (Hanassab, 2006; Lee \& Rice, 2007; Sherry, Thomas, \& Chui, 2010). Therefore, to increase mutual communication and understanding, faculty may need to play an active role in pairing Chinese international students 
with native speakers of English, semester-long mentors, and/or study buddies. Interactions between international students and their American counterparts could also be strengthened by using social network sites (e.g., Twitter and Facebook), which facilitate cultural adaptation (Lin, Peng, Kim, Kim, \& LaRose, 2011).

\section{LIMITATIONS}

Even though steps were taken to enhance trustworthiness, validity and reliability of the data, as discussed in the data quality sections of this paper, this study may be limited in several ways. While the international background of the authors has the potential to enhance credibility, it may also increase the chances of researcher bias. Survey data are limited by the fact that they rarely can be independently verified. Similarly, qualitative data may be subject to interviewees' selective memory, telescoping, exaggeration, and attribution of negative events and outcomes to external forces and positive events and outcomes to one's own agency. Finally, while there was an abundance of research related to LLS, there is a dearth of mixed-method studies that focus on international college students in mainstream classrooms in the U.S; this made discussion of the results more difficult.

\section{CONCLUSION}

All students need an environment where they can maximize their potential. This holds true for the growing number of Chinese international students who move to the U.S. in pursuit of undergraduate and graduate education. Although there is an abundance of literature that explores international students' English learning experience in American language institutes, there is a scarcity of research that examines Chinese international students' LLS use in mainstream college classrooms across disciplines. This study attempts to bridge this gap. The findings that emerged from this QUAL-QUAN mixed-method study supports Firth and Wagner (1997)'s argument that there is value in exploring the relationship between the cognitive theory and social theory of second language acquisition. Grounded in the work of Oxford's (1990) taxonomy of LLS and Gao's (2010) Sociocultural Interpretative Framework, this study made it possible for us to hear how 15 Chinese international students used a variety of direct and indirect LLS to improve their learning. It also made it possible for us to study the influence that 11 factors had on 117 students' strategy use at six universities in the U.S. The findings of this study and the recommendations outlined above can be used to initiate systemic change in the services that are offered to the increasing number of Chinese international students in the U.S.

\section{REFERENCES}

Aouri, Z. E., \& Zerhouni, B. (2017). Motivation and language learning strategies used by Moroccan University EFL science students: A correlational study. Arab World English Journal, 8(2), 5273.

Balci, O. (2017). An investigation of the relationship between language learning strategies and learning styles in Turkish freshman students. English Language Teaching, 10(4), 53-61.

Bartram, B. (2008). Supporting international students in higher education: Constructions, culture and clashes. Teaching in Higher Education, 5(2), 131-154.

Carroll, J. (2015). Tools for teaching in an educationally mobile world. Oxford, UK: Routledge.

Chen, M., \& Huang, L. (2012). Personal type, perceptual style preferences, and strategies for learning English as a foreign language. Social Behavior and personality, 40(9), 1501-1510. 
Cohen, D. (2000). Strategies in learning and using a second language. Beijing: Foreign Language Teaching and Research.

Crede, E., \& Borrego, M. (2014). Understanding retention in US graduate programs by student nationality. Studies in Higher Education, 39(9), 1599-1616.

Creswell, J. W. (2007). Qualitative inquiry and research design choosing among five traditions. Thousand Oaks, CA: Sage Publications.

Creswell, J. W. (2013). Research design: Qualitative, quantitative and mixed methods approaches. Thousand Oaks, CA: Sage Publications.

Edmonson, S., \& Irby, B. (2008). Ten tips for producing a top qualitative study. Boston, MA: Pearson.

Ehrman, M., Oxford, L., (1989). Effects of sex differences, career choice, and psychological type on adult language learning strategies. Modern Language Journal, 73, 1-13.

Firth, A., \& Wagner, J. (1997). On discourse, communication, and (some) fundamental concepts in SLA research. The modern language journal, 81(3), 285-300.

Gan, Z. (2009). 'Asian learners' re-examined: An empirical study of language learning attitudes, strategies and motivation among mainland Chinese and Hong Kong students. Journal of Multicultural and Multicultural Development, 30 (1), 41-58.

Gao, X. (2006). Understanding changes in Chinese students' uses of learning strategies in China and Britain: A socio-cultural re-interpretation. System, 34, 55-67.

Gao, X. (2010). Strategic language learning: The roles of agency and context. Multilingual Matters.

Hanassab, S. (2006). Diversity, international students, and perceived discrimination: Implications for educators and counselors. Journal of Studies in International Education, 10(2), 157-172.

Hatch, A. (2002). Doing qualitative research in education settings. Albany, NY: Suny Press.

Hofstede, G. (1984). Culture's consequences: International differences in work-related values. Newbury Park, CA: Sage.

Hong-Nam, K., \& Leavell, G. (2006). Language learning strategy use of ESL students in an intensive English learning context. System, 34(3), 399-415.

Hong-Nam, K., \& Szabo, S. (2012). Korean university students' language learning strategy use: EFL vs. ESL contexts. College Reading Association Yearbook, 35, 333-353.

Institute of International Education (2016). Open doors 2016 data. Retrieved from https://www.iie.org/Why-IIE/Announcements/2016-11-14-Open-Doors-Data

Kamalizad, J., \& Samuel, M. (2015). Cross context role of language proficiency in learners' use of language learning strategies. The Malaysian Online Journal of Educational Science, 3(1), 1-13.

Kayaoglu, N. M. (2013). Impact of extroversion and introversion on language-learning behaviors. Social Behavior and Personality, 41(5), 819-825.

Kern, R., \& Liddicoat, J. (2008). De l'apprenant au locuteur/acteur. In C. Kramsch, D. Levy \& G. Zarate (Eds.), Precis de plurilinguisme et du pluriculturalisme (pp. 27-65). Paris: Editions des archives contemporaines.

Lee, E. L. (2007). Linguistic and cultural factors in East Asian students' oral participation in U.S. university classrooms. International Education, 36(3), 29-47.

Lee, J. J., \& Rice, C. (2007). Welcome to America? International student perceptions of discrimination. Higher Education, 53, 381-409.

Leedy, P. D., \& Ormrod, J. E. (2005). Practical research: Planning and design (8th ed.). Upper Saddle River, NJ: Pearson.

Li, G., Chen, W., \& Duamu, J. (2010). Determinants of international students' academic performance: A comparison between Chinese and other international students. Journal of Studies in International Education, 14(4), 389-405.

Li, J. (2002). Chinese students' beliefs about and use of L2 learning strategies-an empirical study.

Foreign Language Education, 23 (1), 42-49.

Li, J. (2011). Cultural foundations of learning: East and west. New York, NY: CUP.

Li, X. (2007). Identities and beliefs in ESL writing: From product to processes. TESL Canada Journal, 25(1), 41-64. 
Li, J., \& Qin, X. (2006). Language learning styles and learning strategies of tertiary-level English learners in China. RELC Journal, 37(1), 67-90.

Liao, Y., \& Wei, M. (2014). Academic stress and positive affect: Asian value and self-worth contingency as moderators among Chinese international students. Cultural Diversity and Ethnic Minority Psychology, 20 (1), 107-115.

Liddicoat, J., \& Scarino, A. (2013). Intercultural language teaching and learning. John Wiley \& Sons.

Lillyman, S., \& Bennett, C. (2014). Providing a positive learning experience for international students studying at UK universities: A literature review. Journal of Research in International Education, 13(1), 63-75.

Lin, J., Peng, W., Kim, M., Kim. S., \& LaRose, R. (2011). Social networking and adjustments among international students. New Media \& Society, 14(3), 421-440.

Magno, C., Filho, M. K., Lajom, J. A. (2011). Factors involved in the use of language learning strategies and oral proficiency among Taiwanese students in Taiwan and in the Philippines. The AsiaPacific Education Researchers, 20(3), 489-502.

Mahalingam, K., \& Yunus, M. (2017). Good language learners and their strategies: An insight. Proceedings of the ICECRS, 1(1).

Marshall, C., \& Rossman, G. B., (2016). Designing qualitative research (4th ed.). Thousand Oaks, CA: Sage.

Nasihah, M., \& Cahyono, B. Y. (2017). Language learning strategies, motivation, and writing achievement of Indonesian EFL students. Arab World English Journal, 8(1), 250-263.

Oxford, L. (1989). Strategy Inventory of Language Learning (SILL). Retrieved from http://richarddpetty.files.wordpress.com/2010/03/sill-english.pdf

Oxford, L. (1990). Language learning strategies: What every teacher should know. Boston: Heinle \& Hinle.

Oxford, L., \& Burry-Stock, J. A. (1995). Assessing the use of language learning strategies worldwide with the ESL/EFL version of the Strategy Inventory for Language Learning (SILL). System, 23 (1), 1-23.

Pintrich, P., \& Garcia, T. (1991) Student goal orientation and self-regulation in the college classroom. Advances in Motivation and Achievement 7, 371-402.

Rao, Z. (2016). Language learning strategies and English proficiency: Interpretations from informationprocessing theory. The Language Learning Journal, 44(1), 90-106.

Rao, Z., \& Liu, F. (2011). Effect of academic major on students' use of language learning strategies: A diary study in a Chinese context. Language Learning Journal, 39(1), 43-55.

Russell, A. M. (2010). Assessment of Strategy Inventory of Language Learning (SILL) in students learning a second language. Retrieved from $\mathrm{http} / / /$ scholar.utc.edu/cgi/viewcontent.cgi? article $=1523 \&$ context=theses

Sahragard, R., Khajavi, Y., \& Abbasian, R. (2016). Field of study, learning styles, and language learning strategies of university students: Are there any relations? Innovation in Language Learning and Teaching, 10(3), 255-271.

Sawir, E., Marginson, S., Deumert, A., Nyland, C., \& Ramia, G. (2008). Loneliness and international students: An Australian study. Journal of Studies in International Education, 12(2), 148-180.

Schmit, R., \& Watanable, Y. (2001) Motivation, strategy use and pedagogical preferences. In Dörnyei, Z. and Schmidt, R. (Eds.), Motivation and Second Language Acquisition, pp. 313-352. Manoa, HI: Second Language Teaching and Curriculum Center, University of Hawaii.

Sherry, M., Thomas, P., \& Chui, W. (2010). International students: A vulnerable student population. Higher Education, 60, 33-46.

Squires A. (2009). Methodological challenges in cross-language qualitative research: A research review. Retrieved from https://www.ncbi.nlm.nih.gov/pmc/articles/PMC2784094/

Straker, J. (2016). International student participation in higher education: Changing the focus from "international students" to "participation". Journal of Studies in International Education, 20(4), 299-318. 
Wang, Y. (2012). Transformations of Chinese international students understood through a sense of wholeness. Teaching in Higher Education, 17 (4), 359-370.

Weger, D. (2013). Examining English language learning motivation of adult international learners studying abroad in the U.S. RELC Journal, 44 (1), 87-101.

$\mathrm{Wu}, \mathrm{Q}$. (2015). Re-examine the "Chinese learner": A case study of mainland Chinese students' learning experiences at British universities. Higher Education, 70, 753-766.

$\mathrm{Xu}, \mathrm{X}$. (2011). The relationship between language learning motivation and the choice of language learning strategies among Chinese graduates. International Journal of English Linguistics, 1 (2), 203-212.

Yang, W. (2017). From similarity to diversity: The changing use of language learning strategies in context and language integrated learning at the tertiary level in Taiwan. English Teaching \& Learning, 41(1), 1-32.

Zhao, Q. (2014). An exploration of language anxiety in L2 academic context for Chinese international students in U.S. universities (Doctoral dissertation). Retrieved from ProQuest. (AAI3570324)

\section{Appendix A: Semi-Structured Interview Questions}

\begin{tabular}{|c|c|}
\hline $\begin{array}{l}\text { Four Elements of the } \\
\text { Sociocultural } \\
\text { Interpretative } \\
\text { Framework }\end{array}$ & Interview Questions \\
\hline \multirow[t]{9}{*}{ Part A: Self } & 1. Gender: Male \\
\hline & 2. How old are you? \\
\hline & $\begin{array}{l}\text { 3. Are you pursuing bachelor's degree, master's degree or doctoral } \\
\text { degree? Which year are you in the program? }\end{array}$ \\
\hline & 4. What is your cumulative GPA? \\
\hline & $\begin{array}{l}\text { 5. Have you taken any English proficiency tests (e.g. TOEFL or IELTS)? } \\
\text { If so, what was your score? When did you take it? }\end{array}$ \\
\hline & $\begin{array}{l}\text { 6. What is your learning style (e.g. group/individual learner; visual/verbal; } \\
\text { doer/thinker)? Describe some of the ways in which your learning style } \\
\text { influences your choice of language learning strategies. }\end{array}$ \\
\hline & $\begin{array}{l}\text { 7. What is your attitude towards learning English (positive, neutral, or } \\
\text { negative)? In what ways, does your attitude affect your use of language } \\
\text { learning strategies? }\end{array}$ \\
\hline & $\begin{array}{l}\text { 8. What motivates you to improve your English skills? How do } \\
\text { motivations influence your choice of language learning strategies? }\end{array}$ \\
\hline & $\begin{array}{l}\text { 9. How would you describe your confidence level with regard to learning } \\
\text { English? Do you believe that high confidence increases or inhibits use of } \\
\text { language strategies? }\end{array}$ \\
\hline
\end{tabular}




\begin{tabular}{|c|c|}
\hline & $\begin{array}{l}\text { 10. How would you describe your personality (e.g. extrovert, introvert or } \\
\text { ambivert)? How does your personality influence your strategy use? }\end{array}$ \\
\hline \multirow[t]{4}{*}{$\begin{array}{c}\text { Part B: Situated } \\
\text { Activity }\end{array}$} & $\begin{array}{l}\text { 11. What is your current major? What career would you like to pursue } \\
\text { after graduation? Describe some of the language learning strategies you } \\
\text { have used? In what ways are these choices related to your major and/or } \\
\text { future career? }\end{array}$ \\
\hline & $\begin{array}{l}\text { 12. What are similarities/differences between American and Chinese } \\
\text { instructors' teaching methods? In what ways do teaching methods } \\
\text { influence your use of language learning strategies? Could you provide } \\
\text { examples of how different instructional styles make you to employ } \\
\text { different language learning strategies? }\end{array}$ \\
\hline & $\begin{array}{l}\text { 13. How much do you interact with native English speakers? Could you } \\
\text { provide some examples of how you often interact with them? How do the } \\
\text { interactions influence your choice of language learning strategies? }\end{array}$ \\
\hline & $\begin{array}{l}\text { 14. What are the resources/activities that you have access to on campus } \\
\text { (e.g. library resources, technologies, writing center, conversational partner } \\
\text { club)? How do the resources/activities affect your strategy use? }\end{array}$ \\
\hline \multirow[t]{2}{*}{ Part C: Setting } & $\begin{array}{l}\text { 15. What are the differences between American higher education system } \\
\text { and its Chinese counterpart in terms of assessment (e.g. mid-term and } \\
\text { final exam)? In what ways do these differences impact your strategy use? }\end{array}$ \\
\hline & $\begin{array}{l}\text { 16. What are the differences between Chinese and American universities } \\
\text { in terms of institutional environment? Please explain how these } \\
\text { differences influenced your strategy use. }\end{array}$ \\
\hline \multirow[t]{2}{*}{ Part D: Context } & $\begin{array}{l}\text { 17. How many years have you been studying in the U.S.? Could you } \\
\text { provide examples of how your studying and living experience in the U.S. } \\
\text { influenced your strategy use? Have you observed any differences in your } \\
\text { choice of language learning strategies before and after you come to the } \\
\text { U.S. affected by the linguistic, cultural, and/or social contexts? Could you } \\
\text { provide some details for this change? }\end{array}$ \\
\hline & $\begin{array}{l}\text { 18. How many years did you study English in China? Could you provide } \\
\text { examples of how your studying and living experience in China influenced } \\
\text { your strategy use? What are some of the language learning strategies that } \\
\text { you frequently used while learning English in China? In what ways do } \\
\text { Chinese linguistic, cultural, and/or social contexts impacted your strategy } \\
\text { use? }\end{array}$ \\
\hline Part E: Open-end & $\begin{array}{l}\text { 19. What are other influencing factors in strategic language learning not } \\
\text { mentioned above? }\end{array}$ \\
\hline
\end{tabular}




\section{Appendix B: Factors Influencing English Learning Strategies Survey}

Directions: In the current study, English Learning Strategies (LLS) refer to specific methods/actions that you use to make English learning more enjoyable, self-directed, efficient, and transferable to new situations. The survey that you just completed includes a variety of LLS that you may use while learning English. The following questions ask you about various factors that may influence your LLS use. Please answer the questions and circle the choice that is most appropriate to you.

1. Age:

2. Gender: Female Male

3. University:

4. Major:

5. Which country do you come from?

6. What kind of higher education are you pursuing now?

Bachelor's degree Master's degree Doctoral degree

7. What is your English proficiency level?

Low Intermediate Upper Intermediate Advanced

8. Your primary learning styles (e.g. abstract thinking, visual learning, independent learning, or other styles) influence your English learning methods.
1. Strongly Disagree 2.Disagree
3. Not Sure
4.Agree
5. Strongly Agree

9. Your motivation of learning English influences your English learning methods.
1. Strongly Disagree 2.Disagree
3. Not Sure
4.Agree
5. Strongly Agree

10. The skills and learning content required by your major influence your English learning methods.
1. Strongly Disagree 2.Disagree
3. Not Sure
4.Agree
5. Strongly Agree

11. Active class participation encouraged by your instructors influences your English learning methods.
1. Strongly Disagree 2.Disagree
3. Not Sure
4.Agree
5. Strongly Agree

12. Critical thinking skills promoted by your instructors influence your English learning methods.
1. Strongly Disagree 2.Disagree
3. Not Sure
4.Agree
5. Strongly Agree

13. Your instructors' availability in and after class influences your English learning methods.
1. Strongly Disagree 2.Disagree
3. Not Sure
4.Agree
5. Strongly Agree

14. The variety of assessments (e.g. quizzes, final exam, presentations, group project) used by your instructors influence your English learning methods.
1. Strongly Disagree 2.Disagree
3. Not Sure
4.Agree
5. Strongly Agree

15. Immersion in the authentic English-speaking environment of the U.S. influences your English learning methods.
1. Strongly Disagree 2.Disagree
3. Not Sure
4.Agree
5. Strongly Agree

16. Exposure to the social and cultural values of the American society influences your English learning methods.
1. Strongly Disagree 2.Disagree
3. Not Sure
4.Agree
5. Strongly Agree. 
YAO FU, Ed.D, is an Assistant Professor in the Department of Curriculum and Instruction, University of Wisconsin-Whitewater. Her major research interests lie in the area of teacher education, educational technology, and psychometric scale development. Email: fuy@uww.edu

CRYSTAL MACHADO, Ed.D, is an Associate Professor in the Department of Professional Studies, Indiana University of Pennsylvania. Her major research interests lie in the area of social justice, technology integration, and curriculum and instruction. Email: cmachado@iup.edu

ZHENJIE WENG is a PhD student, majored in Foreign, Second and Multilingual Language Education in the Department of Education and Human Ecology, Ohio State University. Her major research interests lie in the area of ESL/EFL teacher education, second language acquisition, and second language literacy. Email: weng.151@osu.edu 